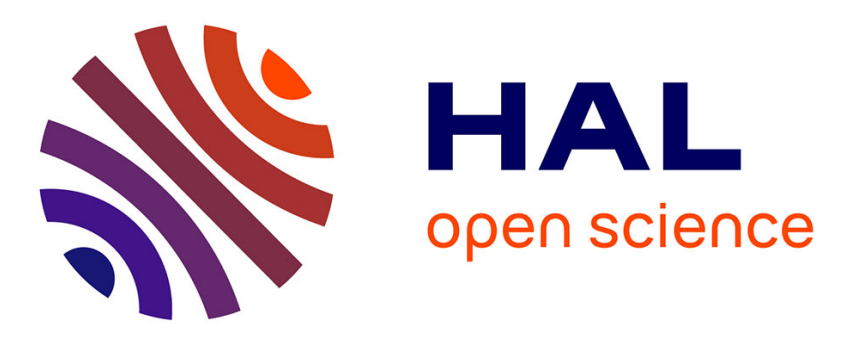

\title{
Proposal of criteria for appraising Goal Attainment Scales used as outcome measures in rehabilitation research
}

\author{
Agata Krasny-Pacini, Jonathan Evans, Mckay Moore Sohlberg, Mathilde \\ Chevignard
}

\section{To cite this version:}

Agata Krasny-Pacini, Jonathan Evans, Mckay Moore Sohlberg, Mathilde Chevignard. Proposal of criteria for appraising Goal Attainment Scales used as outcome measures in rehabilitation research. Archives of Physical Medicine and Rehabilitation, 2016, 97 (1), pp.157-170. 10.1016/j.apmr.2015.08.424 . hal-01203473

\section{HAL Id: hal-01203473 https://hal.sorbonne-universite.fr/hal-01203473}

Submitted on 23 Sep 2015

HAL is a multi-disciplinary open access archive for the deposit and dissemination of scientific research documents, whether they are published or not. The documents may come from teaching and research institutions in France or abroad, or from public or private research centers.
L'archive ouverte pluridisciplinaire HAL, est destinée au dépôt et à la diffusion de documents scientifiques de niveau recherche, publiés ou non, émanant des établissements d'enseignement et de recherche français ou étrangers, des laboratoires publics ou privés. 


\section{Title page}

Running head of no more than 40 character spaces: GAS in rehabilitation research

Title: Proposal of criteria for appraising Goal Attainment Scales used as outcome measures in rehabilitation research

Author(s) full name(s) written as First Name then Last Name, and highest academic degree(s):

Agata Krasny-Pacini ${ }^{1,5,6}, \mathrm{MD}$

Jonathan Evans ${ }^{2}, \mathrm{PhD}$

McKay Moore Sohlberg ${ }^{3}$, PhD

Mathilde Chevignard ${ }^{4,5}, \mathrm{PhD}$

The name(s) of the institution(s), section(s), division(s), and department(s) where the study was performed and the institutional affiliation(s) of the author(s) at the time of the study:

1. Institut Universitaire de Réadaptation Clemenceau-Strasbourg, 45 bd Clemenceau, 67082 Strasbourg, France Paediatric Department and Hautepierre Strasbourg University Hospital, Strasbourg. France

2. Department of Psychological Medicine, Mental Health and Wellbeing, Gartnavel Royal Hospital, 1055 Great Western Rd, Glasgow G12 0XH, Scotland, UK

3. Communication Disorders \& Sciences University of Oregon Eugene Oregon 97403 United States 
4. Rehabilitation Department for Children with Acquired Brain Injury, Hôpitaux de Saint Maurice, 14, rue du Val d'Osne, 94410 Saint Maurice

5. Sorbonne Universités, UPMC Paris 06, UMR 7371, UMR_S 1146, LIB, F-75005, Paris, France

6. Service de Chirurgie Orthopédique Infantile, hôpital de Hautepierre, CHU de Strasbourg, avenue Molière, 67098 Strasbourg cedex

Acknowledgment of any presentation of this material, to whom, when, and where: This work has not been presented yet.

Acknowledgment of financial support, including grant numbers: Writing this paper was partially supported by SOFMER (French society of PMR)-Allergan prize, won by the clinical team of Dr. Krasny-Pacini in October 2012.

We would like to thank Dr. Roumenoff-Turcant from Lyon for her feedback on the paper.

Explanation of any conflicts of interest: The authors report no conflict of interest

Name, address, business telephone number, and e-mail address of corresponding author:

Dr. Agata Krasny-Pacini (corresponding author) Institut Universitaire de Réadaptation Clemenceau-Strasbourg 45 bd Clemenceau 67082 Strasbourg, France Telephone: 0033388211642/47 0033 671-28-41-52 (mobile) 
Fax : $0033388211643 / 1605$

E-mail:agatakrasny@yahoo.com

agata.krasny@ugecam-alsace.fr

The author from whom reprints can be obtained: A. Krasny-Pacini

If reprints are not available, this is stated on the title page.

Clinical trial registration number, if applicable: not applicable 
1

2

3

4

5

6

7

8

9

\title{
Proposed criteria for appraising
}

\author{
Goal Attainment Scales used as
}

\section{outcome measures in rehabilitation}

\author{
research
}

Abstract

Goal Attainment Scaling (GAS) is a method for writing personalized evaluation scales in order to quantify progress toward defined rehabilitation goals. In published literature, GAS methodology is used with different levels of rigor, ranging from precisely written GAS scales, that ensure minimal bias, explicitly describing five levels of goal attainment; to subjective rating of goal attainment by adjectives such as "worse/better than expected", which are transformed into a T-score, wrongly giving the reader the impression of a truly standardized, interval scale. A drawback of GAS methodology is that it is highly dependent on the ability of the GAS setting team/person to generate valid, reliable and meaningful scales, therefore reliability and validity of GAS scales are idiosyncratic to each study. The aims of this article were to: (1) increase awareness of potential sources of bias in GAS processes; (2) propose Goal Attainment Scaling quality appraisal criteria, allowing judgment of the quality of GAS methodology in individual rehabilitation studies; and (3) propose directions to improve GAS 
18 implementation in order to increase its reliability and validity as a research measurement

19 tool. Our proposed quality appraisal criteria are based on critical appraisal of GAS literature,

20 and published GAS validity studies that have demonstrated that precision, validity and

21 reliability can be obtained when using GAS as an outcome measure in clinical trials. We

22 recommend that authors using GAS report accurately how GAS methodology was used

23 based on these criteria.

24 Keywords

goal attainment scaling; outcome measures; goal setting; methodology; scale validity;

26 scale reliability; standards; quality appraisal; guidelines

27 List of abbreviations

GAS: Goal Attainment Scaling

ICF: International Classification of Functioning

IRR: Inter-rater reliability

PMR: Physical Medicine and Rehabilitation

RoM: Range of motion 


\section{Introduction}

Goal Attainment Scaling (GAS) ${ }^{1}$ is a method for writing personalized evaluation scales in order to quantify progress towards defined goals (see practical guidelines ${ }^{2,3,4,5}$ and literature reviews on GAS $\left.{ }^{6,7,8,9,10}\right)$. Goal Attainment Scaling produces an individualized, criterionreferenced measure of a client's goal achievement. Scores can be aggregated to quantify the extent to which a group of clients who are receiving the same type of intervention achieve their personalized rehabilitation goals. One GAS scale is written for each identified rehabilitation goal, with an emphasis on the client's participation in goal selection when possible. Success of the intervention is then quantified on an ordinal scale, typically ranging from -2 (or -3 ) to +2 .

\section{GAS has therefore two intertwined components: (1) GAS methodology is a person-}

centered approach in rehabilitation that emphasizes collaborative goal setting with the establishment of goals and levels of progress that are meaningful to the client; (2) GAS is an outcome measure that can be used both in clinical work and research to assess the effectiveness of an intervention based on personally relevant goals. This paper focuses on the use of GAS as an outcome measure specifically for rehabilitation efficacy research. The reader is referred elsewhere to reviews of the literature on the clinical aspects of collaborative goal setting ${ }^{10,9,11,12}$.

Writing personalized scales through GAS methodology is useful in measuring rehabilitation outcomes, and use of GAS methodology is expanding in research settings, especially in areas where standard scales do not adequately capture a study participant's progress or when a standardized assessment does not exist to measure the construct. GAS methodology offers benefit in the provision of individualized, dependent variables, a critical characteristic for measuring rehabilitation effects. GAS allows use of the same 5-point scale 
method for all clients and therefore aggregation of results independent of goal type. Further, the goal of rehabilitation is to improve clients' activity and participation in natural contexts, but very few measures are designed to ecologically assess performance. By contrast, GAS allows the transformation of goals related to the International Classification of functioning (ICF) activity domains into participation goals in defined contexts where the activities occur 13,14. Feasibility of GAS has been shown across a variety of rehabilitation fields ${ }^{15,16,17,18,19}$. GAS scales are sensitive to change when testing an intervention in rehabilitation ${ }^{20,21,15,16,22,23}$. GAS characteristics in terms of safety, utility and responsiveness are therefore encouraging.

However, in published literature, GAS methodology is used with different levels of rigor, ranging from precisely written GAS scales that ensure minimal bias, explicitly describing five levels of goal attainment; to subjective rating of goal attainment by adjectives such as "worse/better than expected", which are transformed into a T-score, wrongly giving the reader the impression of a truly standardized, interval scale. Although the less rigorous form of GAS methodology can be convenient, useful, fast and practical to use in clinical practice, there is growing concern for its use as an outcome measure in clinical trials ${ }^{24,25}$ and mixed findings as to the reliability ${ }^{24,26}$ and validity of GAS as an outcome measure ${ }^{25}$.

The aims of this paper are to (1) increase awareness of potential sources of bias in GAS processes; (2) propose Goal Attainment Scaling quality appraisal criteria, allowing judgment of the quality of GAS methodology in individual rehabilitation studies; and (3) propose directions to improve GAS implementation in order to increase its reliability and validity as a research measurement tool. This paper is not addressing use of GAS in clinical setting outwith research. 
A literature search using PubMed data base was conducted to ensure that our critical

84

appraisal of the research was inclusive. The keywords "goal attainment scaling" and

"rehabilitation OR therapy" were utilized to identify articles published between 1990 and 2014.

The search returned 179 articles. Twelve articles were excluded because an abstract was not available or because the article was not written in English. A title and abstract review was conducted to identify those articles that evaluated GAS methodology as an outcome measure. Included papers were: (1) Literature reviews on GAS; (2) GAS clinical guidelines; (3) Papers relating to GAS validity and reliability; (4) Papers relating to training in GAS. We purposefully included papers referring to fields outside Physical Medicine and Rehabilitation (PMR), that face the same challenges in evaluating treatment efficacy as rehabilitation does (especially cognitive interventions from the field of psychiatry and developmental disorders). Papers were excluded if they assessed only GAS feasibility or sensitivity to change/responsiveness, without references to its validity and reliability as an outcome measure. This yielded 36 relevant full text papers that were reviewed in order to identify bias in GAS and generate the quality appraisal criteria.

\section{Potential sources of bias in GAS processes and published recommendations for} constructing goal attainment scales.

Usual criticisms of how GAS methodology has been used include: (1) unknown clinimetric qualities of GAS scales used in a given study due to their idiosyncratic nature ${ }^{25}$; (2) subjective scoring, especially if not all levels of the scale are formulated or if descriptions are not precise enough; (3) risk of choosing goals that are not clinically relevant or too easy/too difficult to attain ${ }^{27}$ and therefore do not represent a meaningful or realistic change in function; (4) ordinal (rather than interval) nature of GAS scales ${ }^{28}$ and the lack of equidistance 
106

between GAS levels which cannot be controlled for ${ }^{24}$; (5) the use of a T-score that uses subjective values, especially a subjective weighting of GAS scores and a $\rho$ coefficient assumed to be 0.3 which has not been confirmed in the literature ${ }^{9,28,6}$.

A major drawback of GAS methodology is that it is highly dependent on the ability of the GAS setting team/person to generate valid, reliable and meaningful scales. It has even been proposed that GAS is more a measure of how adequately a therapist can foresee outcome than an outcome measure itself $6,29,30,31,32$. A group of clients may show progress on their GAS scale due to a measurement error, on a GAS scale that is not reliable because of poor interrater reliability, too easy goals, unequal distances between GAS levels or use of subjective criteria for goal attainment. This issue has been raised by Ruble et al. ${ }^{27}$ : "If GAS scores are higher in the experimental conditions [...]one could argue that the targeted outcomes as scaled using GAS were less difficult and easier for [clients] in the experimental group to achieve compared to the control group; that skills were written in more measureable terms and thus easier to be observed and coded in the experimental groups; or that the intervals between each scaled description were unequal and favored the experimental group." (p3). Because these potential biases can threaten reliability of results obtained through GAS, Kiresuk et al. ${ }^{1,33}$ recommended the review of GAS scales by an independent third party, and even suggested that clients should be evaluated on two different sets of GAS scales, developed by two independent research groups ${ }^{1}$ (i.e. treatment success should be independent of how the goals were formulated) ${ }^{1,34}$ to minimize bias. Although few publications address this demanding recommendation ${ }^{35,36}$ it seems crucial that authors using GAS as a research outcome measure provide the reader with information on how the scales were generated and verified (and/or compared between groups on items that may impact 
130

131

132

133

134

136

137

140

141

142

143 Measurable, Achievable, Relevant and Time-determined. Although all authors acknowledge

on GAS scoring as suggested by Ruble et al. ${ }^{27}$ ), in order to provide information on reliability

and validity. Some authors have found encouraging values of GAS reliability and validity $25,15,37,22,35$ (see recent systematic review by Vu et al ${ }^{8}$ ). However the validity and reliability of GAS set by one team (especially an experienced one) does not presume that other GAS scales set by other teams, in other rehabilitation contexts, are valid and reliable ${ }^{27}$. GAS clinimetric qualities depend mainly on how experienced the team is in GAS writing. Grant et al. reported the problems encountered when GAS are used by inexperienced teams, without an independent experienced judge checking the scales ${ }^{12}$.

A series of criteria for writing GAS has been proposed ${ }^{38,1,2,35}$ : (1) each GAS level must be described accurately enough to allow a person who was not involved in the GAS-writing process to easily classify the client at one of the GAS levels described ${ }^{1}$, with no "blank levels" ${ }^{\prime 39}$ (levels not precisely described, which content is inferred from adjacent levels); (2) each scale must represent a single dimension of chang $\mathrm{e}^{12}$; $(3)$ the levels must be measurable and thus defined in terms of observable behaviors ${ }^{6,9,40} ;(4)$ the scales must correspond to goals that are important/meaningful to the client; (5) all the levels must be realistic and attainable (in particular, the +2 level must not correspond to an unexpected or miraculous goal attainment level) ${ }^{1}$; (6) the time scale within which goals must be attained and scales must be scored should be defined in advance; (7) the inter-level differences in difficulty must all be the same ${ }^{41,42}$, i.e. it must be as difficult to progress from -2 to -1 , as from -1 to 0 or from 0 to +1 , etc... and there should be no overlapping and no gap between the levels ${ }^{39}$. Part of these criteria are reflected in the "SMART" acronym ${ }^{38}$ i.e. a goal should be Specific, the need for GAS to be "SMART", few report precautions taken to ensure GAS scales are 
154

155

156

157

158

159

160

161

162

163

164

165

166

167

168

169

170

171

172

173

174

175

176

actually "SMART", and virtually none assesses GAS quality when using it as an outcome measure.

Some authors proposed additional recommendations for GAS when it is used in research: (1) including a training program ${ }^{43,25,15,44}$; (2) establishing all goals prior to randomization ${ }^{45,46}$ or blinding the goal-setter to the patient's treatment/control status ${ }^{47} ;(3)$ testing of interrater reliability for initial and post intervention GAS rating ${ }^{43,46}$; (4) GAS scoring by a blind examiner ${ }^{46}$ who is independent from the team that set the goals $48,49,46,42$ and independent from the therapist providing intervention ${ }^{43,44}$; (5) the use of "control goals" that are not targeted by the intervention ${ }^{6} ;(6)$ evaluation of the patients on two different GAS scales developed by independent therapists (i.e. treatment success must be independent of how the goals were formulated) $1,35,36$; (7) goal-setting by a group (rather than a single therapist or the patient alone), in order to avoid overly simple or unrealistic goals ${ }^{34}$. To our knowledge, the impact of those recommendations on GAS validity and reliability has not yet been studied and few studies follow these guidelines. Their utility and applicability will be discussed in the discussion section of this paper.

\section{Proposed criteria for appraising Goal Attainment Scales}

Because GAS is a relevant and responsive outcome measure in rehabilitation research, but used with great variability that weakens the confidence in the results of trials that use this methodology, there is an urgent need for standards relating to GAS use in rehabilitation efficacy research. Our aim was therefore to propose GAS quality appraisal criteria, that would allow judgment of the quality of GAS methodology in individual rehabilitation studies, that could be used as guidelines to reduce bias, and strengthen GAS validity and reliability. 
Based on our review of the literature, items for the quality appraisal were included if

178 they met one of the following: (1) historically or traditionally recognized quality criteria (such 179 as the "SMART" criteria and Kiresuk et al.'s ${ }^{1,33}$ rules for writing GAS scales); (2) criteria used 180 by teams who obtained and published a good level of inter-rater reliability of their GAS data;

181 (3) criteria used in rehabilitation trials to compare GAS quality across experimental groups;

182 (4) items judged consensually by all authors of this paper as potential key candidates for

183 increasing GAS validity and reliability (even in the absence of literature showing their impact on GAS clinimetric quality). Disagreements between authors on included items are developed in the discussion section.

In selecting criteria, the publications of two teams were particularly useful. In Steenbeek et al.'s methodology ${ }^{35,48,23}$, eight GAS characteristics can be identified to ensure the construction of reliable scales: (1) all five levels of the GAS are precisely described; (2) GAS scales use objective and observable measures based on performance; (3) context of measurement is precisely described and factors that might influence performance are controlled for; (4) initial level is systematically verified after scale is set; (5) an independent, blind assessor scores GAS after intervention; (6) GAS data analysis respects the ordinal nature of GAS, using only raw scores and non-parametric statistics; (7) inter-rater reliability of GAS used in each study is reported; (8) teams are specifically trained to write reliable GAS scales (refer to Steenbeek et al. ${ }^{41}$ for an example of training). controlled trial $(\mathrm{RCT})^{27}$. They suggest the following three key questions to ensure comparability of GAS in different experimental groups: "(a) are the goal and the associated

199 benchmarks relative to each goal described in measurable terms that are comparable between groups (measurability criteria); (b) is the distance between each of the benchmarks 
201 for each scale of equal intervals and comparable between groups (equidistance criteria); and

202 (c) is the level of difficulty between the baseline or starting levels of performance and the 203 targeted outcome goal comparable between groups (difficulty criteria)?" ${ }^{27}$. In a recent

204

205 206 controlled trial ${ }^{50}$, all GAS scales were compared across the two experimental groups on these criteria using a three-point Likert scale, showing the feasibility of comparing GAS scales across groups in RCTs.

We propose 17 GAS quality criteria and these are presented in Table 1. They are broadly grouped into criteria that relate to the content validity of scales ( 4 items), the reliability of scale construction ( 4 items), reliability of scale rating ( 5 items), and an additional four items relating to training, examiner bias, statistical analysis and provision of a sample scale. If GAS is used in a controlled trial, we propose that GAS scales should not only be checked, but also compared between groups, similarly to the methodology proposed by Ruble et al. ${ }^{27}$ for relevant items. For large trials, we propose that at least $20 \%$ of GAS scales be checked/compared.

\section{GAS validity}

INSERT TABLE 1 ABOUT HERE

GAS should be used when standardized assessment does not exist to measure the construct. Content validity of GAS scales is commonly thought to be high if the goal has been collaboratively set with the client wherever possible and this is the first criterion. Goals should be relevant and reflect clinically meaningful change, and this needs to be independently verified. To document the functional relevance of goals, the ICF domain that the goals reflect should be documented. Specificity is core to SMART goal-setting but with several definitions. Our specificity criteria relates to whether goals set specifically relate to 
the intervention being tested - in research it is important to be able to articulate how a particular intervention will lead to achieving the desired goal.

GAS reliability

There are two types of reliability that are particularly important in GAS:

(1) Reliability in the way the scale was constructed (i.e. even with an excellent inter-rater reliability, the scale may not be reliable because of non equidistant levels, erroneous starting pre-intervention levels, too easy goals/GAS levels, and an unspecified time frame for goals' attainment influencing the relative difficulty of attaining a specific goal at the generic postintervention assessment time point). The first four reliability criteria reflect these issues. (2) Reliability in scoring a given GAS scale. Measuring inter-rater reliability (IRR) provides a check on measurement accuracy. The following four items are thought to impact IRR: GAS scales where each level is not precisely described, that use subjective criteria for goal attainment with poor measurability or multidimensional scales, and which do not control for context of measurement, are likely to show lower IRR. Future research is needed to evaluate if respecting those criteria allows better IRR. An adequately measured and reported IRR could release authors from checking all GAS for those items (as training in GAS on those items is likely to generate scales with greater IRR). Because measuring their IRR is time consuming and requires an additional staff member, for large trials, we propose that at least $20 \%$ of GAS scales be tested for IRR (similar to the $20 \%$ of measurement criteria of $\mathrm{N}$-of-1 trial standards ${ }^{51}$ and Ruble's study ${ }^{27}$ ).

Additional items

The final four criteria are included to further reduce potential for bias and increase confidence in GAS in research reports. They relate to: training of staff writing GAS scales; 
247 independence of the person(s) evaluating goal achievement from those who set the goals;

248 use of appropriate statistical analysis methods; and provision of examples of GAS scales in 249 research reports.

\section{Discussion}

The proposed criteria are indisputably challenging to meet. Most research using GAS

does not meet all criteria. However it seems important to set out the highest possible

here are intended for research, where outcome measures must be valid and reliable to

discredit less rigorous but more user-friendly, more practical and less time-consuming uses

of GAS in clinical practice.

259 Controversial criteria

Should GAS use be restricted to collaboratively set goals ? In the literature, goals are

261 often set in collaboration between client/family and therapist 5253545556 , but may also be

262 chosen by the therapist alone ${ }^{57} 58$, or by the client/ family alone ${ }^{57} 59$. Initially, the GAS

263 methodology was invented to assess any goal-directed enterprise, including the functioning

264 of a Crisis Intervention Center ${ }^{34}$ or a hospital-based pharmacy project ${ }^{34}$. Initially goals could

265 therefore be chosen by any professional, with or without participation of the client. In the

266 last twenty years, as rehabilitation moved towards a more person-centered approach ${ }^{60}, \mathrm{GAS}$

267 has become increasingly used as a method for collaborative goal setting, as well as an

268 outcome measure. Literature on brain injury ${ }^{61}$ developed guides and methods of 
collaborative goal setting ${ }^{32} 62910$, and linked use of GAS as an outcome measure with active

270 client participation in goal setting. However GAS may be valuable in PMR domains where

271 client participation in goal selection is not possible (e.g. patients with minimally conscious

272 state, clients with severe intellectual and behavioral impairment...) or is not essential (e.g.

273 early interventions after stroke to prevent contractures and shoulder pain; motor

274 development in infants with attainment of developmental stages that may not be relevant

275 for the family immediately but that are believed to be crucial for future development and

276 future more functional goals...). GAS may also be used to assess effectiveness of an

277 intervention at a health provider level (e.g. goal of reducing pressure ulcer incidence/need

278 for surgery after a group therapeutic education in a spinal cord injury unit). Because

279 collaborative goal-setting is time-consuming for therapists and cognitively demanding for

280 clients (especially those with brain injury), therapists may use collaborative goal setting for

281 some goals, while choosing themselves goals of other domains that are indisputably useful

282 for this client and the focus of the intervention being tested. Therefore we propose here a

283 less restrictive requirement (in the collaborative goal setting item), allowing therapist-

284 chosen goals. In all cases, authors should report if goals were not collaboratively set and

285 provide reasons of their choice.

Most often, GAS scales are set for goal-focused rehabilitation where the goal is directly

trained and GAS represents the degree of progress towards a goal. However it has also been

288 proposed that GAS could be a measure of generalization ${ }^{63}$ : i.e. after training relating to a

289 cognitive function (e.g. executive functions, memory), the use of GAS scales can help assess

290 if training lead to gains in daily life (e.g. GAS relating to activities relying on executive

291 functions such as preparing a schoolbag, GAS relating to memory such as taking medicines

292 on time), without specifically addressing these goals. A valuable approach is to use both a set 
293 of trained goals (and corresponding GAS) and a set of untrained goals (and corresponding

294 GAS) and then to focus the intervention on training the former while using the latter as an 295 untrained ecological generalization measure. Further it is has been proposed that "control" 296 goals $^{6}$ (and related GAS scales) that are not expected to show progression are used, in order 297 to demonstrate the specificity of an intervention (i.e. the client does not just progress on all 298 goals because of general cognitive stimulation or goal-driven motivation, but progresses on 299 the specific goal that is trained or that relates to the trained function needed to achieve an 300 untrained generalization goal).

Authors should report the types of goals chosen in their study, using the ICF. GAS types vary considerably between studies, and do not always measure a meaningful goal, but may remain in the body structure and function (gait pattern ${ }^{64}$, range of motion ${ }^{29}$ ). A clear demonstration of functional benefit to the client in terms of activity and participation is increasingly required in order to show an intervention is effective, and GAS should relate to activity and participation domains as much as possible. When using GAS for body structures, there is a risk that GAS be used as a way of getting round the need for standardized measures. A methodological error often seen with GAS is to convert existing (or even standardized) scales into GAS scales. This is done for two practical reasons: (1) to help as a goal area $\left.{ }^{47}, \mathrm{p} 62\right) ;(2)$ to transform a meaningless number into a relevant and meaningful

313 goal; (3) in order to obtain the same outcome measure for all clients. For example for 314 botulinum toxin treatment, the goal of one client may be to decrease pain, measured on a 315 visual analogue scale, then transformed into a GAS scale depending on the pain level considered as meeting the goal of a treatment; the goal for another client may be to 
decrease equinus (measured in degrees) in a gait analysis laboratory and the range of motion is transformed into a GAS scale presenting a range of ankle positions as the goal.

However such a conversion is done at the expense of losing the linearity of the original measure and although very useful in clinical practice, it is scientifically acceptable only if data is analyzed as truly ordinal (therefore not using T-scores, nor means nor any arithmetical operation) 65662867 .

Can GAS levels be equidistant and GAS data be interval in form? This is possible if a calibration by Rasch Analysis on an "item bank" is carried out as proposed by Tennant et al. $^{24}$, but at the expense of losing GAS adaptability to any goal ${ }^{12}$. Otherwise, GAS levels are very unlikely to be interval despite all precautions, corrections and comparisons used to minimize level inequality bias. Therefore ordinal interpretation of GAS, using rank tests (see Steenbeek et al for an example ${ }^{48}$ ) and excluding all arithmetic procedures ${ }^{66,68,24}$ on GAS scores seems the most reasonable option for GAS data analysis. It is indisputably difficult to set 5 equidistance GAS levels but simple rules can be postulated to facilitate choice of levels (both for goal setters and the external judge who checks GAS levels and compares equidistance between two groups): (1) avoid setting "half levels" ( e.g. -0.5 as proposed by Turner Stokes $\left.{ }^{69}\right) ;(2)$ have all clients start from the same initial score and therefore have all clients assessed on the same number of levels of goal attainment (see ${ }^{5}$ for a discussion on advantages of scoring initial level at -2 or at -1 ).

What type of staff training should be required in order to use GAS in a research protocol? Kiresuk, Smith and Cardillo had proposed that a minimum of one-year experience is required to develop relevant and realistic scales ${ }^{39}$. Basic knowledge of GAS, and experience in collaborative goal setting is not sufficient, as shown by Grant et al ${ }^{62,12}$. Reading a practical guide ${ }^{2,3,5,4}$ may be sufficient for GAS clinical use but not for studies aiming at producing valid 
341 and reliable GAS. A number of authors ${ }^{70,41}$ propose practical training that is largely based on

342 formulating and correcting GAS scales, based on clients' real goals. We recommend that

343 such a practical training be used. This should also raise awareness on GAS quality criteria the

344 study will be judged on, and make GAS scoring easier after the intervention. The quality

345 appraisal here proposed could be the focus of such training.

346 Challenges in GAS methodology

GAS was intended to be a person-centered measure. Is there a risk of losing its person-

centered nature when trying to meet measurement criteria for controlled efficacy trials? The

risk of insisting upon an observable and measurable goal is to exclude family and client appreciation of goal attainment. Appreciation of goal attainment by clients may be

subjective and is affected by a series of factors (self-awareness, denial, memory, high

involvement in goal pursuit) that can bias the perceived attainment of a goal; however goal

identification and measuring its attainment should be person-centered. The challenge for

clinicians and researchers is therefore to understand and analyze the client's (and/or his /her

355 families) goal and transform it into an observable, objective, performance-based measure

356 that can then be used to discuss goal attainment with the client. For example a general goal

357 of "improving my memory" expressed by a client can be transformed into a GAS scale that

358 measures memory functioning in real life situations agreed with the client (e.g. number of

359 medicines taken on time without prompting; number of failed-to-deliver messages in one

360 week...). Scoring GAS based on simple interview should be avoided when possible and

361 creativity used to link subjective goals in difficult domains to more objective goal attainment

362 indicators. For example for a GAS scale on anger management or use of social skills, rather

363 than asking the client to recall how often she/he felt he could cope with his anger or 
364 effectively use social/language skills, an effort should be made to choose indirect indicators

365 of goal attainment such as a review of controlled versus overt anger at the end of a day by

366 the client or proxy rating of social/language skill (how many times he/she

367 initiated/contributed to conversation or was understood) after regular naturally occurring

368 events (outing with friends, family dinner). It is probably the most challenging part of GAS

369 methodology but it has been demonstrated that it is feasible to have GAS that are both

370 person-centered in the choice of goal and objective in the formulation of GAS scales (see

371 Steenbeek et al. for an example ${ }^{35}$ ).

$372 \mathrm{~N}$-of-1 trial literature faces the same challenges and offers growing ingenuous methods

373 for assessment of domains not directly accessible to classical performance-based objective

374 measure. These methods include use of smartphone reminders to self-assess goal

375 attainment at regular periods to decrease memory bias (see ${ }^{71}$ for an example), use of

376 naturally occurring situations monitored in real life by family/proxy to decrease self-

377 awareness bias (see ${ }^{72}$ for an example), use of objective behavioral measures that are

378 thought to reflect the underlying psychological (e.g.: happiness ${ }^{73}$ ) or cognitive (e.g.:

379 functioning at school ${ }^{74,75}$ ) target goals. Future research should extend "goal menus" such as

380 those proposed by Turner-Stokes et al. ${ }^{76}$ to more challenging domains (such as goals relating

381 to social and psychological functions, as well as goals focusing on performance in ecological

382 setting), using also $\mathrm{N}$-of 1 trial literature. When goal attainment indicators are ecological and

383 monitored by the client or proxies, calculating an IRR is impossible (or difficult) and GAS

384 should be checked for items: precise description of all GAS levels, measurability,

385 unidimensionality and context of measurement to increase reliability in scoring. A

386 reasonable compromise between scientific rigor and person-centered approach could be to

387 have for each client at least one ecological client-centered GAS (with the risk of being less 
388

389

390

reliable) and at least one performance-based GAS (with the risk of being less ecological). In all cases, Kiresuk recommended to "anchor scale points with behavioral or other evidence that will be meaningful to the client and readily scored by the rater" ${ }^{\prime 33}$ ( $p 31$ ).

\section{Limitations}

The present article has a number of limitations. Choice of included criteria was not based on a consensual agreement of all major teams using GAS in research but of four teams, from three different countries. The aim of this paper was to raise awareness about the variability of GAS use in published research and the need to build, in future, a consensus on the use of GAS in efficacy research in rehabilitation. Although it may be viewed as a limitation, we purposefully did not validate externally an appraisal score, so that the present guide acts only as a starter for discussion and not a validated tool imposed on other teams that were not included in the writing of the paper.

\section{Conclusion}

Goal Attainment Scaling has the potential to be sensitive to change following treatment and applicable across divergent domains of rehabilitation, making it a useful rehabilitation efficacy research outcome measure. However, GAS is used in studies with variable rigor that impacts its validity and reliability, and therefore reduces the confidence one can have in the results of a trial using GAS as an outcome measure. Clinimetric qualities of GAS are highly dependent on the way GAS scales are written and therefore clinicians, researchers and reviewers cannot rely on published studies of metrological qualities of GAS obtained in different research studies. Researchers should be aware of the risk of bias related to the use of imprecisely written GAS scales in research and make all possible efforts to minimize this 
bias by constructing high quality GAS scales for their clients, following recommendations described here and previously published examples ${ }^{27,48}$. There is a need to develop in the

future a GAS quality appraisal score, similarly to standards used in other rehabilitation

GAS quality in trials using GAS as an outcome measure. We recommend that authors using

\section{References}

1. Kiresuk TJ, Sherman R. Goal Attainment Scaling: A general method for evaluating comprehensive community mental health programs. Comm Mental Health J. 1968;4:443-53.

3. Turner-Stokes L. Goal Attainement Scaling: a practical guide.

2. Bovend'Eerdt TJ, Botell RE, Wade DT. Writing SMART rehabilitation goals and achieving goal attainment scaling: a practical guide. Clin. Rehabil. 2009;23:352-61. http://www.bsrm.co.uk/eventdiaries/LeamingtonSpa2010/Docs/Goal\%20Attainment\% 20Scaling\%20in\%20Rehabilitation\%20\%20a\%20practical\%20guide.pdf.

4. Turner-Stokes L. Goal attainment scaling (GAS) in rehabilitation: a practical guide. Clin. Rehabil. 2009;23:362-70.

6. Schlosser RW. Goal attainment scaling as a clinical measurement technique in communication disorders: a critical review. J. Commun. Disord. 2004;37:217-39. 
7. Hurn J, Kneebone I, Cropley M. Goal setting as an outcome measure: A systematic review. Clin. Rehabil. 2006;20:756-72.

8. Vu M, Law AV. Goal-attainment scaling: a review and applications to pharmacy practice. Res. Soc. Adm. Pharm. RSAP. 2012;8:102-21.

9. Malec JF. Goal Attainment Scaling in Rehabilitation. Neuropsychol. Rehabil. 1999;9:253-75.

10. Bouwens SFM, van Heugten CM, Verhey FRJ. The practical use of goal attainment scaling for people with acquired brain injury who receive cognitive rehabilitation. Clin. Rehabil. 2009;23:310-20.

11. Evans JJ. Goal setting during rehabilitation early and late after acquired brain injury. Curr. Opin. Neurol. 2012;25:651-5.

12. Grant M, Ponsford J. Goal attainment scaling in brain injury rehabilitation: strengths, limitations and recommendations for future applications. Neuropsychol. Rehabil. 2014;24:661-77.

13. Ostensjø S, Oien I, Fallang B. Goal-oriented rehabilitation of preschoolers with cerebral palsy--a multi-case study of combined use of the Canadian Occupational Performance Measure (COPM) and the Goal Attainment Scaling (GAS). Dev. Neurorehabilitation. 2008;11:252-9.

14. McDougall J, Wright V. The ICF-CY and Goal Attainment Scaling: Benefits of their combined use for pediatric practice. Disabil. Rehabil. 2009;31:1362-72.

15. Rushton PW, Miller WC. Goal attainment scaling in the rehabilitation of patients with lower-extremity amputations: A pilot study. Arch. Phys. Med. Rehabil. 2002;83:771-5.

16. Khan F, Pallant JF, Turner-Stokes L. Use of goal attainment scaling in inpatient rehabilitation for persons with multiple sclerosis. Arch. Phys. Med. Rehabil. 2008;89:652-9.

17. Hazard RG, Spratt KF, McDonough CM, Carayannopoulos AG, Olson CM, Reeves V, et al. The impact of personal functional goal achievement on patient satisfaction with progress one year following completion of a functional restoration program for chronic 
disabling spinal disorders. Spine. 2009;34:2797-802.

18. Lewis VJ, Dell L, Matthews LR. Evaluating the feasibility of Goal Attainment Scaling as a rehabilitation outcome measure for veterans. J. Rehabil. Med. 2013;45:403-9.

19. Hanssen KT, Saltytè Benth J, Beiske AG, Landrø NI, Hessen E. Goal attainment in cognitive rehabilitation in MS patients. Neuropsychol. Rehabil. 2015;25:137-54.

20. Rockwood K, Howlett S, Stadnyk K, Carver D, Powell C, Stolee P. Responsiveness of goal attainment scaling in a randomized controlled trial of comprehensive geriatric assessment. J. Clin. Epidemiol. 2003;56:736-43.

491

492

493

494

495

496

497

498

499

500

501

502

503

504

505

21. Turner-Stokes L, Williams H, Johnson J. Goal attainment scaling: does it provide added value as a person-centred measure for evaluation of outcome in neurorehabilitation following acquired brain injury? J. Rehabil. Med. Off. J. UEMS Eur. Board Phys. Rehabil. Med. 2009;41:528-35.

22. Rockwood K, Joyce B, Stolee P. Use of goal attainment scaling in measuring clinically important change in cognitive rehabilitation patients. J. Clin. Epidemiol. 1997;50:581-8.

23. Steenbeek D, Gorter JW, Ketelaar M, Galama K, Lindeman E. Responsiveness of Goal Attainment Scaling in comparison to two standardized measures in outcome evaluation of children with cerebral palsy. Clin. Rehabil. 2011;25:1128-39.

24. Tennant A. Goal attainment scaling: current methodological challenges. Disabil. Rehabil. 2007;29:1583-8.

25. Steenbeek D, Ketelaar M, Galama K, Gorter JW. Goal attainment scaling in paediatric rehabilitation: a critical review of the literature. Dev. Med. Child Neurol. 2007;49:5506.

26. Bovend'Eerdt TJH, Dawes H, Izadi H, Wade DT. Agreement between two different scoring procedures for goal attainment scaling is low. J. Rehabil. Med. Off. J. UEMS Eur. Board Phys. Rehabil. Med. 2011;43:46-9.

27. Ruble L, McGrew JH, Toland MD. Goal Attainment Scaling as an Outcome Measure in Randomized Controlled Trials of Psychosocial Interventions in Autism. J. Autism Dev. Disord. 2012;42:1974-83. 
28. MacKay G, Somerville W, Lundie J. Reflections on goal attainment scaling (GAS): cautionary notes and proposals for development. Educ. Res. 1996;38:161-72.

29. Turner-Stokes L, Baguley IJ, De Graaff S, Katrak P, Davies L, McCrory P, et al. Goal attainment scaling in the evaluation of treatment of upper limb spasticity with botulinum toxin: a secondary analysis from a double-blind placebo-controlled randomized clinical trial. J. Rehabil. Med. Off. J. UEMS Eur. Board Phys. Rehabil. Med. 2010;42:81-9.

30. Cytrynbaum S, Ginath Y, Birdwell J, Brandt L. Goal Attainment Scaling A Critical Review. Eval. Rev. 1979;3:5-40.

31. Simeonsson RJ, Jr DBB, Huntington GS, Brandon L. Scaling and attainment of goals in family-focused early intervention. Community Ment. Health J. 1991;27:77-83.

32. Ertzgaard P, Ward AB, Wissel J, Borg J. Practical considerations for goal attainment scaling during rehabilitation following acquired brain injury. J. Rehabil. Med. Off. J. UEMS Eur. Board Phys. Rehabil. Med. 2011;43:8-14.

33. Kiresuk TJ, Smith A, Cardillo JE, editors. Goal attainment scaling: Applications, theory, and measurement. Hillsdale, NJ, England: first published by Lawrence Erlbaum Associates, Inc, edition published in 2013 by Psychology Press, Hove, East Sussex, UK.; 1994.

34. Kiresuk TJ, Lund SH, Larsen NE. Measurement of goal attainment in clinical and health care programs. Drug Intell. Clin. Pharm. 1982;16:145-53.

35. Steenbeek D, Ketelaar M, Lindeman E, Galama K, Gorter JW. Interrater reliability of goal attainment scaling in rehabilitation of children with cerebral palsy. Arch. Phys. Med. Rehabil. 2010;91:429-35.

36. $P S, K R, R a F, D I S$. The use of goal attainment scaling in a geriatric care setting. J. Am. Geriatr. Soc. 1992;40:574-8.

37. Palisano RJ. Validity of goal attainment scaling in infants with motor delays. Phys. Ther. 1993;73:651-8; discussion 658-60. 
38. King GA, McDougall J, Palisano RJ, Gritzan J, Tucker MA. Goal Attainment Scaling: its use in evaluating pediatric thearpy programs. Phys. Occup. Ther. Pediatr. 2000;19:31-52.

39. Smith A. Introduction and overview. In: Kiresuk TJ, Cardillo JE, editors. Goal attainment scaling: Applications, theory, and measurement. Hillsdale, NJ, England: Lawrence Erlbaum Associates, Inc; 1994. p. 1-14.

40. Stolee P, Stadnyk K, Myers AM, Rockwood K. An individualized approach to outcome measurement in geriatric rehabilitation. J. Gerontol. A. Biol. Sci. Med. Sci. 1999;54:M641-7.

41. Steenbeek D, Ketelaar M, Galama K, Gorter JW. Goal Attainment Scaling in paediatric rehabilitation: a report on the clinical training of an interdisciplinary team. Child Care Health Dev. 2008;34:521-9.

42. Jones MC, Walley RM, Leech A, Paterson M, Common S, Metcalf C. Using goal attainment scaling to evaluate a needs-led exercise programme for people with severe and profound intellectual disabilities. J. Intellect. Disabil. JOID. 2006;10:317-35.

43. Mailloux Z, May-Benson TA, Summers CA, Miller L, Brett-Green B, Burke JP, et al. Goal attainment scaling as a measure of meaningful outcomes for children with sensory integration disorders. Am. J. Occup. Ther. Off. Publ. Am. Occup. Ther. Assoc. 2007;61:254-9.

44. Shefler G, Canetti L, Wiseman H. Psychometric properties of goal-attainment scaling in the assessment of mann's time-limited psychotherapy. J. Clin. Psychol. 2001;57:971-9.

45. Palisano RJ, Haley SM, Brown DA. Goal attainment scaling as a measure of change in infants with motor delays. Phys. Ther. 1992;72:432-7.

46. Ottenbacher KJ, Cusick A. Discriminative Versus Evaluative Assessment: Some Observations on Goal Attainment Scaling. Am. J. Occup. Ther. 1993;47:349-54.

47. Zaza C, Stolee P, Prkachin K. The application of goal attainment scaling in chronic pain settings. J. Pain Symptom Manage. 1999;17:55-64.

48. Steenbeek D, Meester-Delver A, Becher JG, Lankhorst GJ. The effect of botulinum toxin type $A$ treatment of the lower extremity on the level of functional abilities in children with cerebral palsy: evaluation with goal attainment scaling. Clin. Rehabil. 
594

595

596

597

598

599

600

601

602

603

604

605

606

607

608

609

610

611

612

613

614

615

616

617

618

619

620

621

622

623

624

625

626

627

628

629

630

631

632
2005;19:274-82.

49. Sakzewski L, Boyd R, Ziviani J. Clinimetric properties of participation measures for 5- to 13-year-old children with cerebral palsy: a systematic review. Dev. Med. Child Neurol. 2007;49:232-40.

50. Ruble LA, Dalrymple NJ, McGrew JH. The Effects of Consultation on Individualized Education Program Outcomes for Young Children With Autism: The Collaborative Model for Promoting Competence and Success. J. Early Interv. 2010;32:286-301.

51. Tate RL, Perdices M, Rosenkoetter U, Wakim D, Godbee K, Togher L, et al. Revision of a method quality rating scale for single-case experimental designs and $n$-of- 1 trials: the 15-item Risk of Bias in N-of-1 Trials (RoBiNT) Scale. Neuropsychol. Rehabil.

2013;23:619-38.

52. Bergsma $D$, Baars-Elsinga A, Sibbel J, Lubbers $P$, Visser-Meily A. Visual daily functioning of chronic stroke patients assessed by goal attainment scaling after visual restorative training: an explorative study. Top. Stroke Rehabil. 2014;21:400-12.

53. Peirone E, Goria PF, Anselmino A. A dual-task home-based rehabilitation programme for improving balance control in patients with acquired brain injury: a single-blind, randomized controlled pilot study. Clin. Rehabil. 2014;28:329-38.

54. Phillips MF, Robertson Z, Killen B, White B. A pilot study of a crossover trial with randomized use of ankle-foot orthoses for people with Charcot-Marie-tooth disease. Clin. Rehabil. 2012;26:534-44.

55. Wallen MA, O'Flaherty SJ, Waugh M-CA. Functional outcomes of intramuscular botulinum toxin type a in the upper limbs of children with cerebral palsy: a phase II trial. Arch. Phys. Med. Rehabil. 2004;85:192-200.

56. Bjornson K, Hays R, Graubert C, Price R, Won F, McLaughlin JF, et al. Botulinum toxin for spasticity in children with cerebral palsy: a comprehensive evaluation. Pediatrics. 2007;120:49-58.

57. Lowe K, Novak I, Cusick A. Repeat injection of botulinum toxin A is safe and effective for upper limb movement and function in children with cerebral palsy. Dev. Med. Child Neurol. 2007;49:823-9. 
58. Bovend'Eerdt TJ, Dawes H, Sackley C, Izadi H, Wade DT. An integrated motor imagery program to improve functional task performance in neurorehabilitation: a single-blind randomized controlled trial. Arch. Phys. Med. Rehabil. 2010;91:939-46.

59. Berge SR Ten, Boonstra AM, Dijkstra PU, Hadders-Algra M, Haga N, Maathuis CGB. A systematic evaluation of the effect of thumb opponens splints on hand function in children with unilateral spastic cerebral palsy. Clin. Rehabil. 2012;26:362-71.

60. Leach E, Cornwell P, Fleming J, Haines T. Patient centered goal-setting in a subacute rehabilitation setting. Disabil. Rehabil. 2009;32:159-72.

61. Malec JF, Smigielski JS, DePompolo RW. Goal attainment scaling and outcome measurement in postacute brain injury rehabilitation. Arch Phys Med Rehabil. 1991;72:138-43.

62. Grant M, Ponsford J, Bennett PC. The application of Goal Management Training to aspects of financial management in individuals with traumatic brain injury. Neuropsychol. Rehabil. 2012;22:852-73.

63. Krasny-Pacini A, Limond J, Evans J, Hiebel J, Bendjelida K, Chevignard M. ContextSensitive Goal Management Training for Everyday Executive Dysfunction in Children After Severe Traumatic Brain Injury. J. Head Trauma Rehabil. 2014;

64. Mall V, Heinen F, Siebel A, Bertram C, Hafkemeyer U, Wissel J, et al. Treatment of adductor spasticity with BTX-A in children with CP: a randomized, double-blind, placebo-controlled study. Dev. Med. Child Neurol. 2006;48:10-3.

65. Merbitz C, Morris J, Grip JC. Ordinal scales and foundations of misinference. Arch. Phys. Med. Rehabil. 1989;70:308-12.

66. Stucki G, Daltroy L, Katz JN, Johannesson M, Liang MH. Interpretation of change scores in ordinal clinical scales and health status measures: The whole may not equal the sum of the parts. J. Clin. Epidemiol. 1996;49:711-7.

67. Grenville J, Lyne P. Patient-centred evaluation and rehabilitative care. J. Adv. Nurs. 1995;22:965-72.

68. Küçükdeveci AA, Tennant A, Grimby G, Franchignoni F. Strategies for assessment and outcome measurement in physical and rehabilitation medicine: an educational review. 
69. Turner-Stokes L, Williams H. Goal attainment scaling: a direct comparison of alternative rating methods. Clin. Rehabil. 2010;24:66-73.

70. Cardillo JE. Goal Setting, Follow-up and Goal Monitoring. In: Kiresuk TJ, Smith A, editors. Goal attainment scaling: Applications, theory, and measurement. Hillsdale, NJ, England: Lawrence Erlbaum Associates, Inc; 1994. p. 39-59.

680

681

682

683

684

685

686

687

688

689

690

691

692

693

694

695

696

697

698

699

700

701

702

71. Arco L. Neurobehavioural treatment for obsessive-compulsive disorder in an adult with traumatic brain injury. Neuropsychol. Rehabil. 2008;18:109-24.

72. Baldwin VN, Powell T. Google Calendar: A single case experimental design study of a man with severe memory problems. Neuropsychol. Rehabil. 2014;1-20.

73. Logan KR, Jacobs HA, Gast DL, Murray AS, Daino K, Skala C. The Impact of Typical Peers on the Perceived Happiness of Students with Profound Multiple Disabilities. Res. Pract. Pers. Sev. Disabil. 1998;23:309-18.

74. Feeney TJ, Ylvisaker M. Context-sensitive behavioral supports for young children with TBI: short-term effects and long-term outcome. J. Head Trauma Rehabil. 2003;18:3351.

75. Feeney $T$, Ylvisaker M. Context-sensitive cognitive-behavioural supports for young children with TBI: A replication study. Brain Inj. 2006;20:629-45.

76. Ashford S, Jackson D, Turner-Stokes L. Goal setting, using goal attainment scaling, as a method to identify patient selected items for measuring arm function. Physiotherapy. 2015;101:88-94. 


\begin{tabular}{|c|c|c|c|}
\hline $\begin{array}{c}\text { Quality appraisal } \\
\text { items }\end{array}$ & Item description & $\begin{array}{l}\text { Examples of reported criteria, extracted from } \\
\text { rehabilitation effectiveness studies and/or published } \\
\text { methods that satisfy criteria. }\end{array}$ & $\begin{array}{l}\text { Potential for bias arising from failure } \\
\text { to report criteria and/or utility of } \\
\text { reporting the criterion. }\end{array}$ \\
\hline \multicolumn{4}{|c|}{ Content Validity } \\
\hline $\begin{array}{l}\text { Collaborative goal } \\
\text { setting }\end{array}$ & $\begin{array}{l}\text { The client/family is included in goal } \\
\text { selection, when possible and } \\
\text { appropriate. If goals are therapist- } \\
\text { chosen, they rely on a comprehensive } \\
\text { assessment (and when possible, a } \\
\text { client/family interview), identifying key } \\
\text { target domains for intervention. }\end{array}$ & $\begin{array}{l}\text { "GAS was used to assess functional and participation changes from } \\
\text { both a parent and therapist perspective" } \\
\text { "Using a semi-structured interview [...] } 3 \text { performance goals were } \\
\text { identified at baseline by parents and child with the research } \\
\text { physical therapist. The same } 3 \text { goals were then structured for GAS } \\
\text { through semi-structured interview and by collaboration between } \\
\text { research therapist, parent and child.". }\end{array}$ & $\begin{array}{l}\text { Collaborative goal setting allows evaluation of } \\
\text { intervention efficacy for personally meaningfu } \\
\text { goals, rather than generic goals and is a core } \\
\text { component of GAS methodology. } \\
\text { Involvement of the client in goal setting is } \\
\text { considered to increase the likelihood that the } \\
\text { intervention has direct impact on client's daily } \\
\text { life. }\end{array}$ \\
\hline $\begin{array}{l}\text { Relevance/ } \\
\text { importance }\end{array}$ & $\begin{array}{l}\text { GAS scales have been verified by an } \\
\text { external judge to check for the } \\
\text { relevance of chosen goals and to check } \\
\text { if GAS levels represent clinically } \\
\text { meaningful change. }\end{array}$ & $\begin{array}{l}\text { In a study of infants with motor delays, Palisano }{ }^{3} \text { used a } 5 \text { point } \\
\text { scale to assess: (1) importance of goals for motor development } \\
\text { ranging from "unimportant or inappropriate" to "important for } \\
\text { development and for function"; (2)extent each level represents an } \\
\text { important progress based on number of paired levels that } \\
\text { represent important change ("none" to "all four paired levels"). } \\
\text { Cardillo " proposed a } 5 \text { point scale ranging from "1: No relevance" } \\
\text { to "5: Total relevance". }\end{array}$ & $\begin{array}{l}\text { If the target goal is unimportant to the client, } \\
\text { irrelevant for function or does not correspond } \\
\text { to a clinically meaningful change, progress on } \\
\text { the GAS scale has no clinical relevance. } \\
\text { At the extreme, an intervention could be } \\
\text { proven to be effective, by writing clinically and } \\
\text { personally irrelevant goals but showing } \\
\text { statistically significant progress on the } \\
\text { corresponding GAS scale. }\end{array}$ \\
\hline $\begin{array}{l}\text { ICF classification of } \\
\text { goal types }\end{array}$ & $\begin{array}{l}\text { GAS themes correspond to functional } \\
\text { domains. } \\
\text { Authors report the ICF domain the GAS } \\
\text { relate to. }\end{array}$ & $\begin{array}{l}\text { In a study of botulinum toxin effectiveness, Turner-Stokes }{ }^{5} \text { et al. } \\
\text { report exhaustively the types of goals for treatment, categorizing } \\
\text { them into ICF domains (Body function: } 46 \text { GAS, including } 12 \text { GAS on } \\
\text { passive movement/range; Activities and Participation: } 119 \text { GAS, } \\
\text { divided into: Upper limb activities: } 30 \text { GAS; Mobility: } 11 \text { GAS; Self } \\
\text { care: } 57 \text { GAS; Domestic and Community: } 21 \text { GAS). } \\
\text { Phillips et al. " } \text { report precise examples of target goals in different } \\
\text { ICF domain (e.g.: "driving for } 40 \text { minutes without feet going floppy"; } \\
\text { "standing in supermarket queue for } 3 \text { minutes without support"). }\end{array}$ & $\begin{array}{l}\text { If GAS scales assess change in body structures } \\
\text { (e.g. RoM, spasticity), the reader may wrongly } \\
\text { conclude that the intervention had an impact } \\
\text { on meaningful activity and participation, } \\
\text { because most readers associate GAS with } \\
\text { functional daily life goals. } \\
\text { It is therefore crucial that authors report the } \\
\text { proportion of goals in each ICF domain, } \\
\text { especially if some of goals do not correspond } \\
\text { to functional domains. }\end{array}$ \\
\hline Specificity & $\begin{array}{l}\text { GAS scales have been verified by an } \\
\text { external judge to check for specificity to } \\
\text { the aim of the intervention. } \\
\text { If GAS is used as a generalization } \\
\text { measure to untrained goals, GAS } \\
\text { should be specific to the function the }\end{array}$ & $\begin{array}{l}\text { In an intervention for executive dysfunction in children }{ }^{7} \text {, a specific } \\
\text { goal of intervention was to manage a cooking recipe unaided, } \\
\text { which was trained on different recipes; a generalization goal was to } \\
\text { be able to prepare school bag which was not trained (but stepwise } \\
\text { processing taught was expected to generalize to this untrained } \\
\text { goal). Although important to the children, goals such as "have more } \\
\text { friends", were not included as they were not specific to the aim of }\end{array}$ & $\begin{array}{l}\text { Goals that are relevant to the client, but } \\
\text { unrelated to the specific intervention, are } \\
\text { unlikely to show progress and may } \\
\text { erroneously lead to the conclusion that the } \\
\text { intervention is not effective (this is especially a } \\
\text { risk in replication studies). }\end{array}$ \\
\hline
\end{tabular}




\begin{tabular}{|c|c|c|c|}
\hline & intervention is aiming to improve. & $\begin{array}{l}\text { intervention, but they might have been used as "control" goals, not } \\
\text { expected to be attained. }\end{array}$ & \\
\hline \multicolumn{4}{|c|}{ Reliability } \\
\hline \multicolumn{4}{|c|}{ Reliability of scale construction } \\
\hline $\begin{array}{l}\text { Equidistance of } \\
\text { levels }\end{array}$ & $\begin{array}{l}\text { GAS scales have been verified by an } \\
\text { external judge to check if difficulty from } \\
\text { one level to the next is roughly equal. }\end{array}$ & $\begin{array}{l}\text { Equidistance of GAS levels was assessed and compared statistically } \\
\text { nbetween two experimental groups using a } 3 \text { point scale by Ruble et } \\
\text { al. }{ }^{89} \text { : "1: None or only one of the descriptions are equilibrated } \\
\text { appropriately in reference to the goal; } 2: \text { Two of the descriptions } \\
\text { are equilibrated appropriately in reference to the goal; } 3 \text { : All of the } \\
\text { descriptions relative to the goal are equilibrated and scaled } \\
\text { appropriately)". }\end{array}$ & $\begin{array}{l}\text { If GAS scores are higher in the experimental } \\
\text { conditions, one could argue that the intervals } \\
\text { between each scaled description are unequal } \\
\text { and favor the experimental group. } \\
\text { This problem is particularly serious if } \\
\text { parametric statistics and T-scores are used. }\end{array}$ \\
\hline $\begin{array}{l}\text { Pre-intervention } \\
\text { performance }\end{array}$ & $\begin{array}{l}\text { Pre-intervention performance has been } \\
\text { verified and corresponds to initial level } \\
\text { described in the scale. } \\
\text { Pre-intervention score is comparable } \\
\text { across groups (same number of clients } \\
\text { starting from -2 and -1). }\end{array}$ & $\begin{array}{l}\text { "At first baseline, GAS were created based on parent's, teacher's } \\
\text { and school assistant's concerns. After two months (second } \\
\text { baseline), the paper versions of the scales were scored by parents, } \\
\text { teachers and school assistants who were not aware that the } \\
\text { intervention had not started yet. Their answers allowed } \\
\text { readjustment of the scales, through the following rules: Scales that } \\
\text { scored } 0 \text { were reformulated in order to have the pre-intervention } \\
\text { level (measured at second baseline) corresponding to }-1 \text { by fixing } \\
\text { more challenging } 0,+1 \text { and }+2 \text { scores. Scales scoring }-2 \text { or }-1 \text { were } \\
\text { not reformulated. Scales scoring }+1 \text { or }+2 \text { pre-intervention were } \\
\text { removed as the goal seemed attained without intervention or } \\
\text { unreliably scored due to potential enthusiasm effect and motivation } \\
\text { driving perceived change independently from intervention that had } \\
\text { not started ". }\end{array}$ & $\begin{array}{l}\text { GAS scales are constructed uniquely for each } \\
\text { client, according to his/her initial level in } \\
\text { relation to the target goal. If pre-intervention } \\
\text { level is not verified, the whole scale may be } \\
\text { unreliably constructed (erroneous starting } \\
\text { point of the scale generating inappropriate } \\
\text { next levels). }\end{array}$ \\
\hline $\begin{array}{l}\text { Attainability/ } \\
\text { difficulty }\end{array}$ & $\begin{array}{l}\text { GAS scales have been verified by an } \\
\text { external judge to check for their } \\
\text { difficulty/attainability. }\end{array}$ & $\begin{array}{l}\text { Ruble et al. compared GAS scales for difficulty in a trial of cognitive } \\
\text { intervention: "1: Skill is very close to what the child is already } \\
\text { described as able to perform (very easy); } 2 \text { : The child is able to } \\
\text { perform the skill in limited ways compared to what is written in the } \\
\text { objective (limited people, prompts, or places [...]]; } 3 \text { : The child is } \\
\text { unable to perform skill with anyone, anywhere, or with any prompts } \\
\text { compared to what is written in the objective (difficult)". }{ }^{89} \\
\text { In a study of infants with motor delays, Palisano }{ }^{3} \text { asked experts to } \\
\text { decide which of the } 5 \text { GAS level the child was most likely to achieve } \\
\text { after } 3 \text { months, aiming at a maximum of } 0 \text { and a minimum of } \\
\text { extreme }-2 \text { and }+2 \text { scores, if GAS levels were decided correctly. } \\
\text { Cardillo }{ }^{4} \text { reported that realism of the expected level of outcome }\end{array}$ & $\begin{array}{l}\text { An experimental group may falsely present } \\
\text { higher GAS scores post intervention because } \\
\text { GAS scales were formulated with easier levels } \\
\text { of goal attainment. }\end{array}$ \\
\hline
\end{tabular}




\begin{tabular}{|c|c|c|c|}
\hline & & $\begin{array}{l}\text { "for each goal, for this patient, at this time, in this mental health } \\
\text { service" was assessed by a scale ranging from 1: much too difficult } \\
\text { to 5: much too easy. He also reviews other methods that use } 3 \text { or } 5 \\
\text { point scales using "pessimistic/realistic/optimistic" terms. Such } \\
\text { scales could be easily used in PMR to compare } \\
\text { attainability/difficulty of goals between two groups. }\end{array}$ & \\
\hline Time-specificity & $\begin{array}{l}\text { Authors specify if/how longer-term } \\
\text { goals were adapted to the specific time } \\
\text { frame of the research study. } \\
\text { In the case of multiple assessment, } \\
\text { authors specify which assessment was } \\
\text { taken as the target moment for goal } \\
\text { achievement. }\end{array}$ & $\begin{array}{l}\text { In the RCT of Lowe et al }{ }^{1} \text {, children were evaluated at } 13 \text { different } \\
\text { time points. It is not reported which assessment point was taken as } \\
\text { the reference to choose the } 0 \text { level (level that will most probably be } \\
\text { attained after intervention) - criterion unmet. }\end{array}$ & $\begin{array}{l}\text { Goal difficulty across experimental groups may } \\
\text { have been unequal, at a given assessment } \\
\text { point, due to differences in time-frames for } \\
\text { goal completion. }\end{array}$ \\
\hline \multicolumn{4}{|c|}{ Reliability of scale rating } \\
\hline $\begin{array}{l}\text { Inter-rater } \\
\text { reliability (IRR) }\end{array}$ & $\begin{array}{l}\text { Inter-rater reliability of GAS scales is } \\
\text { reported. }\end{array}$ & $\begin{array}{l}\text { In a study of Steenbeek et al. in cerebral palsy, inter-rater reliability } \\
\text { was reported based on two judges using video-taped performance } \\
\text { of each goal }{ }^{10} \text {. }\end{array}$ & $\begin{array}{l}\text { Reliability of GAS set by one team (especially } \\
\text { an experienced one) does not presume that } \\
\text { other GAS scales set by other teams, in other } \\
\text { rehabilitation contexts, are reliable. Therefore } \\
\text { IRR should be reported for the specific GAS } \\
\text { scales generated in each study. }\end{array}$ \\
\hline \multicolumn{4}{|l|}{ Criteria affecting IRR } \\
\hline $\begin{array}{l}\text { Precise description } \\
\text { of all levels }\end{array}$ & $\begin{array}{l}\text { Five GAS levels have been precisely } \\
\text { described pre-intervention for each } \\
\text { scale. }\end{array}$ & $\begin{array}{l}\text { “Goal: Reducing weekly shopping expenditure } \\
\text { Total weekly food/household shopping expenditure = } \\
\text { +2: less than } \$ 42.99 \\
+1: \$ 46.99-\$ 43.00 \\
0: \$ 54.00-\$ 47.00 \\
-1: \$ 63.00-\$ 54.01 \\
-2: \text { greater than } \$ 63.00^{\prime \prime} 11\end{array}$ & $\begin{array}{l}\text { When all levels of the scales have not been } \\
\text { precisely decided and described prior to } \\
\text { intervention, authors often use adjectives such } \\
\text { as "worse than expected", "much better than } \\
\text { expected", to score goal attainment. This is a } \\
\text { subjective appreciation that may be useful } \\
\text { clinically but is too imprecise to objectively } \\
\text { determine intervention efficacy. }\end{array}$ \\
\hline Measurability & $\begin{array}{l}\text { GAS scales have been verified by an } \\
\text { external judge to check for } \\
\text { measurability. } \\
\text { Subjective and general goals are } \\
\text { transformed into more objective and } \\
\text { measurable goal attainment indicators. }\end{array}$ & $\begin{array}{l}\text {-good measurability: observable and objective performance with } \\
\text { specified task (e.g.: A child's goal to fall less is assessed through "an } \\
\text { obstacle course including jumping and quick changes of walking } \\
\text { direction. The therapist encourages [the child] to complete the } \\
\text { course within 3min. Instruction "Walk the obstacle course fast and } \\
\left.\text { don't fall"; GAS levels: -1: falls } 3 \text { times, } 0: \text { falls } 2 \text { times }[. . .]^{12}\right) . " \\
\text {-unclear measurability: subjective criteria, or scored based on } \\
\text { interviews rather than direct observation of performance (e.g.: "I } \\
\text { am able to express opinions and feelings two times or more per } \\
\left.\text { week [...]", with no self-assessment method specified }{ }^{13}\right) \text {. } \\
\text { See Ruble et al. for an example of assessment of measurability of }\end{array}$ & $\begin{array}{l}\text { A goal that is not measurable will yield } \\
\text { subjective scores, biased by clients' or } \\
\text { therapists' feelings/ state of mind at the } \\
\text { moment of scoring rather than a reliable } \\
\text { measure of goal attainment. }\end{array}$ \\
\hline
\end{tabular}




\begin{tabular}{|c|c|c|c|}
\hline & & social and cognitive goals ${ }^{89}$. & \\
\hline Unidimensionality & $\begin{array}{l}\text { GAS scales have been verified by an } \\
\text { external judge to check for } \\
\text { unidimensionality. }\end{array}$ & $\begin{array}{l}\text {-Example of a non-unidimensional scale: "-1: I use 0-1 coping skills } \\
\text { consistently and feel depressed and angry more than } 40 \% \text { of the } \\
\text { time.; } 0: \text { I use 2-3 coping skills consistently and feel depressed and } \\
\text { angry } 25-40 \% \text { of the time [...]"13 } \\
\text {-Example of a truly unidimensional scale: “.... -1: Manages to eat a } \\
\text { bowl of mashed potatoes unaided but takes more than } 15 \text { minutes; } \\
\text { 0: Eats a bowl of mashed potatoes in } 11 \text { to } 15 \text { minutes... }\end{array}$ & $\begin{array}{l}\text { Non-unidimensional goals are impossible to } \\
\text { score as progress on one dimension may not } \\
\text { be accompanied by progress on another } \\
\text { dimension and generate situations where GAS } \\
\text { cannot be scored (see Grant }{ }^{15} \text { for an example). } \\
\text { Bi (Multi) dimensional GAS's should be split } \\
\text { into two (or more) unidimensional GAS prior } \\
\text { to intervention start. }\end{array}$ \\
\hline $\begin{array}{l}\text { Context of } \\
\text { measurement }\end{array}$ & $\begin{array}{l}\text { Context of performance measurement } \\
\text { is clearly defined (prompts, cueing, } \\
\text { support, amount of help/guidance, } \\
\text { location...) and is controlled for during } \\
\text { GAS rating. } \\
\text { OR } \\
\text { Changes in context are carefully } \\
\text { manipulated across the GAS levels, with } \\
\text { one change per level at a time }{ }^{16} \text {. }\end{array}$ & $\begin{array}{l}\text { e.g.: setting/prompting/guidance: "in order to create an irregular } \\
\text { surface, a ladder is placed horizontally at a height of } 15 \mathrm{~cm} \text {, the girl } \\
\text { is asked to walk barefoot without orthosis, as quickly as possible, } \\
\text { through the rungs over a distance of } 8 \text { meters. Only if she falls a } \\
\text { therapist will help her holding one of her hands." } 17 \\
\text { e.g.: "GAS level -1: Prepares school bag but requires constant verbal } \\
\text { guidance from the parents or teacher; GAS level 0: Manages to } \\
\text { prepare the school bag using a check-list of necessary steps and } \\
\text { under supervision; GAS level+1: Manages to prepare school bag } \\
\text { alone, using a check-list of necessary steps; GAS level +2: No } \\
\text { supervision required, child only occasionally forgets items."14 } 7\end{array}$ & $\begin{array}{l}\text { Context of measurement influences } \\
\text { performance on a given target goal } \\
\text { (environment, fatigue, help provided...). These } \\
\text { factors must be controlled in order to increase } \\
\text { GAS scoring reproducibility. } \\
\end{array}$ \\
\hline \multicolumn{4}{|c|}{ Other criteria } \\
\hline Training & $\begin{array}{l}\text { Researchers setting the GAS with the } \\
\text { client and verifying GAS have received } \\
\text { training in writing GAS, have practiced } \\
\text { GAS writing, are aware of potential } \\
\text { sources of bias in GAS, and are } \\
\text { experienced in the goal } \\
\text { domain/population. }\end{array}$ & $\begin{array}{l}\text { Although training in GAS writing is reported as being important }{ }^{18} \text {, } \\
\text { and successful training methods have been published }{ }^{17} \text {, most } \\
\text { studies do not report on therapists' training. Some studies report to } \\
\text { which practical GAS guide }{ }^{16} 19 \text { they refer to, but without mention of } \\
\text { training }^{2021} \text {. } \\
\text { Those mentioning training do not explain the type of training (e.g.: } \\
\text { "Experienced pediatric occupational therapists were trained in and } \\
\text { completed the GAS collaboratively with the families, thus enhancing } \\
\text { the reliability of the GAS" }{ }^{22} \text { ). }\end{array}$ & $\begin{array}{l}\text { Given the numerous and complex potential } \\
\text { sources of bias in GAS processes, a team that } \\
\text { is not experienced in using GAS methodology } \\
\text { is unlikely to produce valid and reliable GAS. } \\
\text { Further, a team without specific experience in } \\
\text { the goal domain or the specific population } \\
\text { with whom the intervention is tested, will } \\
\text { have difficulty in predicting what can be } \\
\text { attained in a given time-frame, even if } \\
\text { experienced in GAS methodology in another } \\
\text { domain (risk unrealistic goals, unequal } \\
\text { difficulty across clients, irrelevant goals to the } \\
\text { specific population...). }\end{array}$ \\
\hline Examiner bias & $\begin{array}{l}\text { The person scoring the GAS at the end } \\
\text { of the intervention is independent from } \\
\text { the team who set the GAS (and } \\
\text { independent from the team that } \\
\text { provided the intervention although the } \\
\text { latter is not a GAS specific criterion). }\end{array}$ & $\begin{array}{l}\text { e.g.: "Goals were chosen and set before the patient was allocated } \\
\text { to a group [...] goal attainment was scored by an independent } \\
\text { assessor at post-treatment and at follow-up." }{ }^{20} \text {. } \\
\text { e.g.: "The therapist-GAS was scored from video by blind evaluators. } \\
\text { The parent-GAS was scored by two blinded occupational } \\
\text { therapists."1. }\end{array}$ & $\begin{array}{l}\text { If the same person sets the GAS and scores } \\
\text { them, he/she is likely to be biased towards } \\
\text { scoring a maximum of } 0 \text { ("attained as } \\
\text { expected"). He/she may rely on memory of } \\
\text { initial performance and subjective impression } \\
\text { of improvement to score ambiguous progress. } \\
\text { The independence of assessor should also be }\end{array}$ \\
\hline
\end{tabular}




\begin{tabular}{|c|c|c|c|}
\hline & & & $\begin{array}{l}\text { respected when goals are client/family chosen } \\
\text { when GAS is an outcome measure in research, } \\
\text { (in contrast with clinical practice, where GAS } \\
\text { scoring by the client may be relevant and } \\
\text { appropriate). }\end{array}$ \\
\hline Statistical analysis & $\begin{array}{l}\text { Ordinal nature of GAS scales is } \\
\text { preserved using non parametric } \\
\text { statistics (rank tests, medians, } \\
\text { boxplots). }\end{array}$ & $\begin{array}{l}\text { e.g.:"It was decided not to use the popular T score in order to } \\
\text { preserve the ordinal nature of the data [...] group effects were } \\
\text { demonstrated by testing the difference between all medians, [...] } \\
\text { using a two-tailed Wilcoxon signed ranks test",10. }\end{array}$ & $\begin{array}{l}\text { The performance of arithmetic operations } \\
\text { such as T-scores on ordinal data is scientifically } \\
\text { not valid }{ }^{23} \text { and should be discouraged, as it } \\
\text { yields erroneous interpretation of data. In } \\
\text { GAS, the problem is multiplied by } \\
\text { characteristics of the T-score formulae } \\
\text { (unknown true value of } \rho \text {, T-score variation } \\
\text { according to the number of goals per client } \\
\text { even at equal degree of attainment, highly } \\
\text { subjective weighting of goals which, although } \\
\text { clinically meaningful, introduces further } \\
\text { potential arithmetic incoherence in the final T- } \\
\text { score). }\end{array}$ \\
\hline Example of GAS & $\begin{array}{l}\text { One (or more) example of a typical GA } \\
\text { full scale, extracted from the trial, is } \\
\text { provided. } \\
\text { A list of chosen goals is reported. }\end{array}$ & $\begin{array}{l}\text { Some authors provide an example of full GAS scale in the paper } \\
24 \text { in the methods or results section. } \\
\text { Examples of goal types can be given (1) by providing examples of } \\
\text { goal in the paper } 252627{ }^{28} ;(2) \text { by reporting all chosen goals in } \\
\text { appendix }{ }^{25} ; \text {; (3) by reporting goal type and frequency of each type } \\
\text { without providing an exhaustive goal list }{ }^{22} 2910 .\end{array}$ & $\begin{array}{l}\text { Providing examples allows the reader a quick } \\
\text { judgment/idea of goal type, precision of goal } \\
\text { and levels description, measurability, } \\
\text { unidimensionality of GAS. } \\
\text { The lack of GAS examples contributes to make } \\
\text { GAS seem like an abstract outcome measure: } \\
\text { unlike standardized scales, the reader cannot } \\
\text { build a representation of the target goals of } \\
\text { the intervention. } \\
\text { Therefore, reporting all goals in an appendix } \\
\text { and providing example(s) of full GAS scales } \\
\text { (representative of different domains } \\
\text { measured) should be encouraged to increase } \\
\text { interpretability. }\end{array}$ \\
\hline \multicolumn{4}{|c|}{ TABLE 1: Goal Attainment Scaling (GAS) methodology quality appraisal for rehabilitation efficacy studies } \\
\hline
\end{tabular}


1. Lowe K, Novak I, Cusick A. Repeat injection of botulinum toxin A is safe and effective for upper limb movement and function in children with cerebral palsy. Dev. Med. Child Neurol. 2007;49:823-9.

2. Bjornson K, Hays R, Graubert C, Price R, Won F, McLaughlin JF, et al. Botulinum toxin for spasticity in children with cerebral palsy: a comprehensive evaluation. Pediatrics. 2007;120:49-58.

3. Palisano RJ. Validity of goal attainment scaling in infants with motor delays. Phys. Ther. 1993;73:651-8; discussion 658-60.

4. Cardillo JE. Goal Setting, Follow-up and Goal Monitoring. In: Kiresuk TJ, Smith A, editors. Goal attainment scaling: Applications, theory, and measurement. Hillsdale, NJ, England: Lawrence Erlbaum Associates, Inc; 1994. p. 39-59.

5. Turner-Stokes L, Baguley IJ, De Graaff S, Katrak P, Davies L, McCrory P, et al. Goal attainment scaling in the evaluation of treatment of upper limb spasticity with botulinum toxin: a secondary analysis from a double-blind placebo-controlled randomized clinical trial. J. Rehabil. Med. Off. J. UEMS Eur. Board Phys. Rehabil. Med. 2010;42:81-9.

6. Phillips MF, Robertson Z, Killen B, White B. A pilot study of a crossover trial with randomized use of ankle-foot orthoses for people with Charcot-Marietooth disease. Clin. Rehabil. 2012;26:534-44.

7. Krasny-Pacini A, Limond J, Evans J, Hiebel J, Bendjelida K, Chevignard M. Context-Sensitive Goal Management Training for Everyday Executive Dysfunction in Children After Severe Traumatic Brain Injury. J. Head Trauma Rehabil. 2014;

8. Ruble LA, Dalrymple NJ, McGrew JH. The Effects of Consultation on Individualized Education Program Outcomes for Young Children With Autism: The Collaborative Model for Promoting Competence and Success. J. Early Interv. 2010;32:286-301.

9. Ruble L, McGrew JH, Toland MD. Goal Attainment Scaling as an Outcome Measure in Randomized Controlled Trials of Psychosocial Interventions in Autism. J. Autism Dev. Disord. 2012;42:1974-83.

10. Steenbeek D, Meester-Delver A, Becher JG, Lankhorst GJ. The effect of botulinum toxin type A treatment of the lower extremity on the level of functional abilities in children with cerebral palsy: evaluation with goal attainment scaling. Clin. Rehabil. 2005;19:274-82. 
11. Grant M, Ponsford J, Bennett PC. The application of Goal Management Training to aspects of financial management in individuals with traumatic brain injury. Neuropsychol. Rehabil. 2012;22:852-73.

12. Steenbeek D, Ketelaar M, Lindeman E, Galama K, Gorter JW. Interrater reliability of goal attainment scaling in rehabilitation of children with cerebral palsy. Arch. Phys. Med. Rehabil. 2010;91:429-35.

13. Malec JF. Goal Attainment Scaling in Rehabilitation. Neuropsychol. Rehabil. 1999;9:253-75.

14. Krasny-Pacini A, Hiebel J, Pauly F, Godon S, Chevignard M. Goal Attainment Scaling in rehabilitation: A literature-based update. Ann. Phys. Rehabil. Med. 2013;56:212-30.

15. Grant M, Ponsford J. Goal attainment scaling in brain injury rehabilitation: strengths, limitations and recommendations for future applications. Neuropsychol. Rehabil. 2014;24:661-77.

16. Bovend'Eerdt TJ, Botell RE, Wade DT. Writing SMART rehabilitation goals and achieving goal attainment scaling: a practical guide. Clin. Rehabil. 2009;23:352-61.

17. Steenbeek D, Ketelaar M, Galama K, Gorter JW. Goal Attainment Scaling in paediatric rehabilitation: a report on the clinical training of an interdisciplinary team. Child Care Health Dev. 2008;34:521-9.

18. Mailloux Z, May-Benson TA, Summers CA, Miller LJ, Brett-Green B, Burke JP, et al. Goal attainment scaling as a measure of meaningful outcomes for children with sensory integration disorders. Am. J. Occup. Ther. Off. Publ. Am. Occup. Ther. Assoc. 2007;61:254-9.

19. Turner-Stokes L. Goal attainment scaling (GAS) in rehabilitation: a practical guide. Clin. Rehabil. 2009;23:362-70.

20. Bovend'Eerdt TJ, Dawes H, Sackley C, Izadi H, Wade DT. An integrated motor imagery program to improve functional task performance in neurorehabilitation: a single-blind randomized controlled trial. Arch. Phys. Med. Rehabil. 2010;91:939-46. 
21. Mendelson AD, McCullough C, Chan A. Integrating self-management and exercise for people living with arthritis. Health Educ. Res. $2011 ; 26: 167-77$.

22. Wallen MA, O'Flaherty SJ, Waugh M-CA. Functional outcomes of intramuscular botulinum toxin type a in the upper limbs of children with cerebral palsy: a phase II trial. Arch. Phys. Med. Rehabil. 2004;85:192-200.

23. Tennant A. Goal attainment scaling: current methodological challenges. Disabil. Rehabil. 2007;29:1583-8.

24. Dahlberg CA, Cusick CP, Hawley LA, Newman JK, Morey CE, Harrison-Felix CL, et al. Treatment efficacy of social communication skills training after traumatic brain injury: a randomized treatment and deferred treatment controlled trial. Arch. Phys. Med. Rehabil. 2007;88:1561-73.

25. Bergsma D, Baars-Elsinga A, Sibbel J, Lubbers P, Visser-Meily A. Visual daily functioning of chronic stroke patients assessed by goal attainment scaling after visual restorative training: an explorative study. Top. Stroke Rehabil. 2014;21:400-12.

26. Peirone E, Goria PF, Anselmino A. A dual-task home-based rehabilitation programme for improving balance control in patients with acquired brain injury: a single-blind, randomized controlled pilot study. Clin. Rehabil. 2014;28:329-38.

27. Berge SR Ten, Boonstra AM, Dijkstra PU, Hadders-Algra M, Haga N, Maathuis CGB. A systematic evaluation of the effect of thumb opponens splints on hand function in children with unilateral spastic cerebral palsy. Clin. Rehabil. 2012;26:362-71.

28. Jones MC, Walley RM, Leech A, Paterson M, Common S, Metcalf C. Using goal attainment scaling to evaluate a needs-led exercise programme for people with severe and profound intellectual disabilities. J. Intellect. Disabil. JOID. 2006;10:317-35.

29. Wallen M, O'Flaherty SJ, Waugh M-CA. Functional Outcomes of Intramuscular Botulinum Toxin Type A and Occupational Therapy in the Upper Limbs of Children With Cerebral Palsy: A Randomized Controlled Trial. Arch. Phys. Med. Rehabil. 2007;88:1-10. 